\title{
ALEJANDRO ALVA BALDERRAMA
}

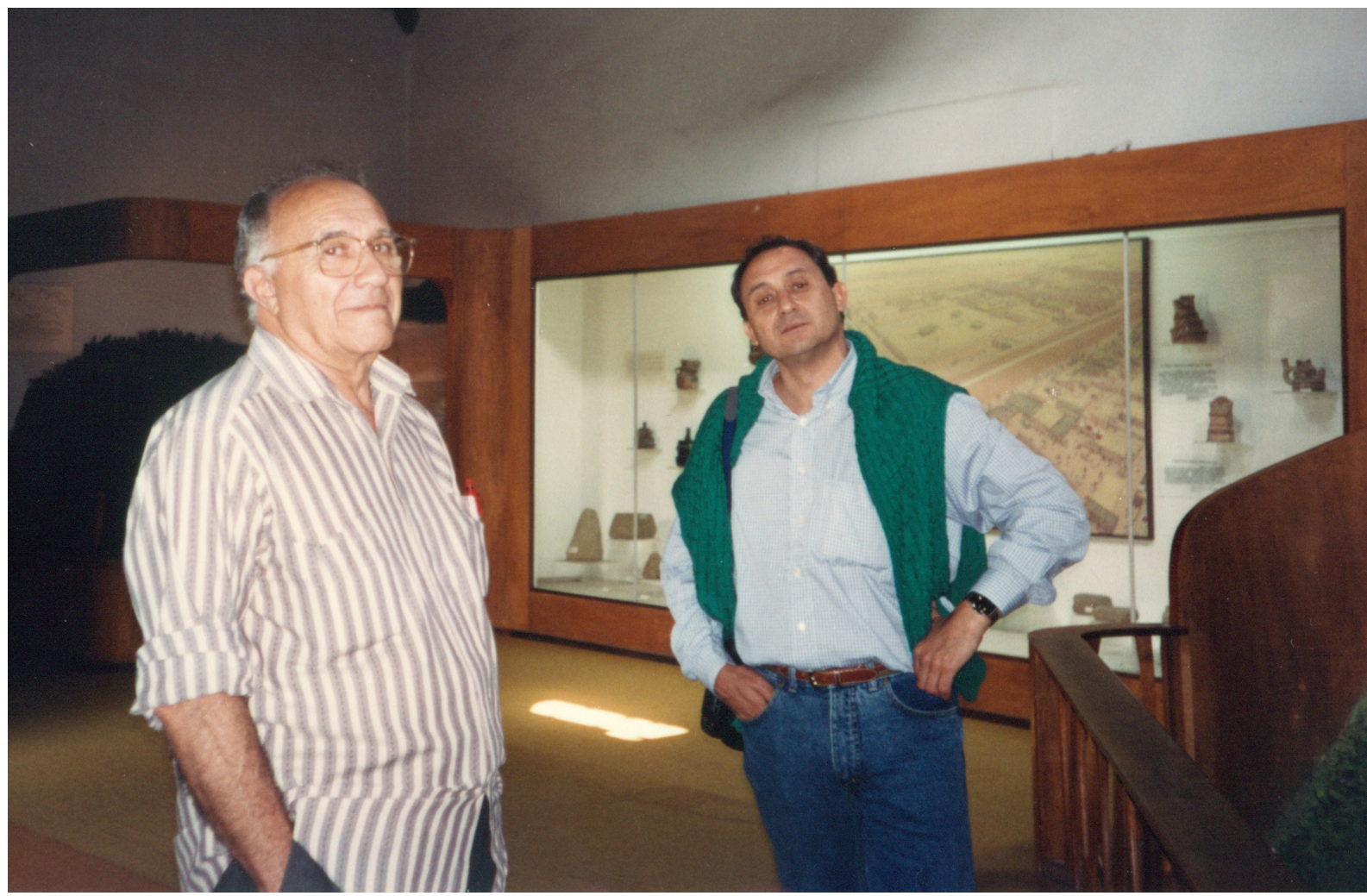

Alejandro Alva Balderrama (a la derecha) visitando el Museo Nacional de Arqueología, Antropología e Historia del Perú (Lima) en compañía de su padre Alejandro Alva Manfredi, ambos importantes arquitectos patrimonialistas peruanos.

Fuente. Fototeca personal Sra. Ena Alva Balderrama, Lima 2016.

El pasado mes de marzo se cumplieron ya dos años del sensible fallecimiento del amigo Alejandro Alva Balderrama, colega que conocí a inicios de 1971, cuando Alejandro era estudiante de la Facultad de Arquitectura de la Universidad Ricardo Palma y fue encargado, por esa Universidad, de ayudar en el dictado del curso Historia de la Arquitectura Peruana, entonces a mi cargo. El curso desgraciadamente tuvo que ser interrumpido al tener yo que viajar a Roma, ganador de una beca del Gobierno italiano. Para Alejandro, esa ciudad sería después -desde 1978- su definitivo destino profesional.

Con estas breves líneas, dedicadas a su memoria, no se desea repetir los ya conocidos y justos tributos rendidos por sus colegas de ICCROM, del Getty Institute y del ICOMOS internacional. ${ }^{1}$

Ya recordaba el arquitecto Luis Miró Quesada Garland en su última visita a Roma que él mismo había sido testigo personal del encuentro de los que fueron sus genitores en los años 40 en la ciudad de Cajamarca, historia que Alejandro y yo escuchamos creo ya en los 90.

1. Publicados online, accesibles en http://www.iccrom.org/it/alejandro-alva-balderrama-1945-2014/, http://www.getty.edu/conservation/publications_resources/newsletters/pdf/v29n1.pdf y http://ip51.icomos.org/ fleblanc/in-memoriam/alva-balderrama-alejandro/ im_alva_alejandro.html 
devenir Vol. 2, N4, JULIO-DICIEMBRE 2015, PP. 5-6 - IN MEMORIAM I ISSN 2312-7570

UNIVERSIDAD NACIONAL DE INGENIERÍ, LIMA

Su padre, Alejandro Alva Manfredi, fue también un apreciado arquitecto dedicado al partimonio nacional y un alto dirigente del Instituto Nacional de Cultura en el Perú. Fue además su jefe cuando, primero en Juli y después en el pueblo de Challapampa, se hizo la evaluación del famoso retablo de Bernardo Bitti, magnífica obra de arte que después desapareció y hoy, recuperada, luce nuevamente su belleza, como hace algún tiempo recordaba Víctor Pimentel Gurmendi, estimado arquitecto y restaurador.

Alejandro llegó para especializarse al ICCROM de Roma gracias al apoyo del arquitecto José Correa Orbegoso, entonces dirigente del patrimonio nacional. Tras terminar su curso (ARC) fue elegido como asistente, y muy pronto -por su capacidad y reconocida seriedad- llegó a ser director de la Unidad de Arquitectura y Sitios Arqueológicos, donde programó importantes cursos y actividades.

Más de una vez regresó a la patria, especialmente a Chan Chan (Trujillo). Integró cursos y seminarios originados en Grenoble con CRATerre, PAT y Gaia de Roma, ante la difícil condición del patrimonio construido en tierra cruda. Despertaba, durante sus actividades, la sincera estima de todos los estudiantes inscritos.

Fue también gracias a él que muchas veces fui encargado de dictar lecciones, y enviado en 1992 a representar a ICCROM durante un curso CICOP en la ciudad de Santa Cruz de Tenerife (Canarias), siendo yo ya miembro del Consejo y del Comité Académico del ICCROM.

Alejandro deja con su temprana ausencia un vacío en Roma, un gran recuerdo y sus afectos, entre ellos la adorada hija suya y de Catherine Antomarchi, otra columna portante del ICCROM, institución de la cual Alejandro se jubiló en 2005. No dejó antes de darme consejos cuando fui encargado de programas de la Cooperación Italiana para la conservación del patrimonio del MercoSur, y tampoco abandonó después válidas iniciativas sobre programación y enseñanza de la conservación del patrimonio edificado.

Prof. Dr. Arq. Leonardo Mattos-Cárdenas 